\title{
Climate Change: Miserable Green House Gases
}

\section{Kumar Bahadur Darjee}

Climate change is the any long term significant changes in the 'average whether' by the effect of heat trapping due to the increased presence of green house gases(Carbon dioxide, Methane, Nitrous oxide, Ozone and Halocarbons) in the atmosphere(Green house effect) that a given region experiences.

Carbon dioxide $\left(\mathrm{CO}_{2}\right)$ is the most important atmospheric green house gas. Its' annual emission grew by about $80 \%$ between 1997 and 2004 (ICIMOD 2008).

Climate change involves, perhaps most serious changes in the frequency and magnitude of whether events. There is widespread agreement that globing warming is associated with the most severe fluctuations, particularly in combination with intensified monsoon circulation. Climate change, land use change, and population dynamics are the major drivers of environmental change. These drivers have influenced ecosystem services, and in many cases have had a negative impact on the livelihood of people and increased their economic and environmental vulnerability.

According to third assessment report of Intergovernmental Panel on Climate change (IPCC 2001), air temperature of earths' surface increased at $0.4^{\circ} \mathrm{C}$ to $0.8^{\circ} \mathrm{C}$ during last 100 years. Rather danger subject showed by that report is, $1.4^{\circ} \mathrm{C}$ to $5.8^{\circ} \mathrm{C}$ air temperature of earths' surface will be increased by green house effect in coming 100 years period, which results $0.88 \mathrm{~m}$ increment in sea level.

Carbon dioxide $\left(\mathrm{CO}_{2}\right)$, Methane $\left(\mathrm{CH}_{4}\right)$, Nitrous oxide $\left(\mathrm{NO}_{2}\right)$, Hydroflurocarbon (HFCs), and Perflurocarbon (PFCs) are exiting in atmosphere which is commonly called as green house gases. There is significant contribution of green house gases to the global warming as $\mathrm{CO}_{2}$ contributes $56 \%$, HFCs contributes $23 \%, \mathrm{CH}_{4}$ contributes $14 \%$ and $\mathrm{NO}_{2}$ contributes $7 \%$, in temperature increment (Prof. Dr. R.P. Chaudhari 2007)

In present scenario of green house gases $\mathrm{CO}_{2}$ is increasing in such a quantity that it covers more than $50 \%$ responsibility in atmospheric temperature increment. In $1800, \mathrm{CO}_{2}$ was estimated that there was $280 \mathrm{ppm}$ quantity in the atmosphere. Now it has increased to $350 \mathrm{ppm}$ and it is forecasted that it would be $560 \mathrm{ppm}$ till 2030 . HFCs and PFCs play significant role in temperature increment, even though it has low emission. But its effect is accounted for 1,300-2,400 times greater than that of $\mathrm{CO}_{2}$. Similarly, $\mathrm{NH} 4$ has 20 times grater effect than $\mathrm{CO}_{2}$, but its existence is low in atmosphere and $0.7 \mathrm{ppm}$ was estimated before industrialization, now it is found 1.783 ppm in quantity (WCN 2006). Likewise, $\mathrm{NO}_{2}$ has 200 times greater effect than $\mathrm{CO}_{2}$ and exists in environment up to 120 years.

These gases are increasing by nature itself and human interference in industrialization and technological intervention. Notwithstanding, these gases are indispensable for living beings, its

Kathmandu Forestry College, Kathmandu, Nepal, kumarlekali@gmail.com 
production/emission should be controlled.

Overwhelming scientific consensus indicates that global warming is a real and significant threats our health, our economy and our environment. Climate change will have long term impact on the nations' security as wars break out over food and water supplies around the world (Lewis Smith, environment reporter2008). Hundreds of millions of environmental refugees will seek new places to live. Security services would be challenged by the number of refugees, and the government would need to consider stronger broader controls (Report: Oxford research group)

Attempts to tackle the new problems with old strategy would be doomed. If government simply responds with traditional attempts to maintain the status quo and control insecurity, they will ultimately fail. The security consequences of climate change will not just manifest themselves "over there", there will be domestic security concerns for both developed and developing nations alike (Cris Abbott)

There are four possible imperative movements that should be executed in no time. Firstly, expediently respect to the downtrodden and marginalized people by making them aware on climate change and its effect. Secondly, effective and efficient management of forest should be materialized for enlarging greenery. Thirdly, scientific agricultural crop production should be initiated for minimizing green house gases emission. And fourthly, attention should be paid for promotion of Clean Development Mechanism.

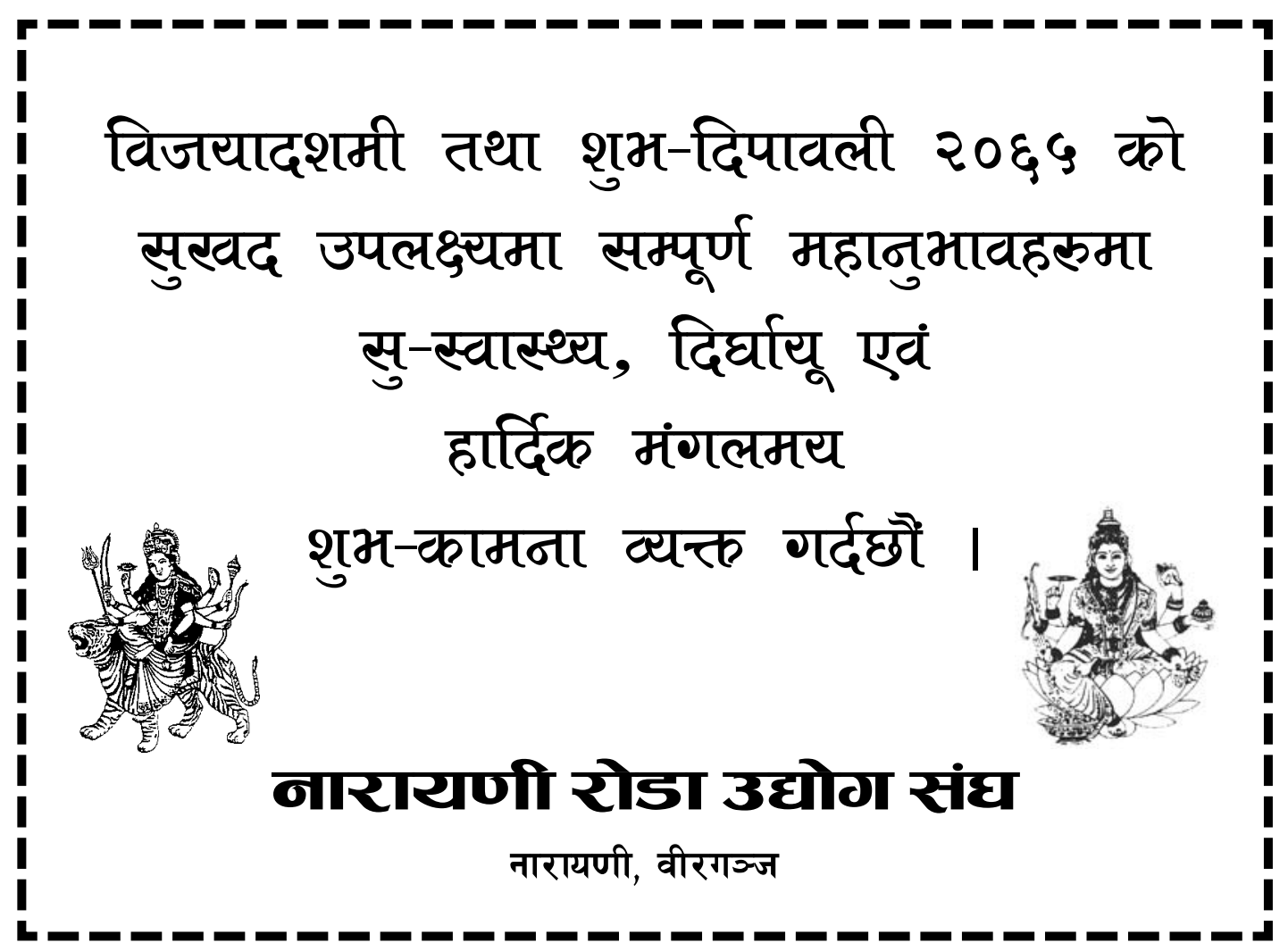

